\title{
Illegal dogfighting: sport or crime?
}

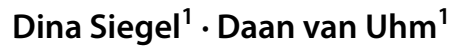

Accepted: 19 May 2021 /Published online: 10 August 2021

(c) The Author(s) 2021

\begin{abstract}
In recent years there is increasing public attention for dog fighting in Europe. This article focuses on this phenomenon in the Netherlands: its organisation, various actors, modus operandi and possible involvement of organized crime. This qualitative research is based on semi-structured interviews, analysis of police files, observations and online methods. As the result of criminalisation, dogfighting in the Netherlands went underground, creating an illegal market and a sub-culture of dogmen and dogwomen involved. Reputation, status and trust are among the most prominent features of this sub-culture, which is manifested in their analysed communications.
\end{abstract}

Keywords Dog fighting $\cdot$ Dog crime $\cdot$ Criminalization $\cdot$ Criminal networks

\section{Introduction}

There is no single clear explanation as to why dogfighting ${ }^{1}$ continues to be such a popular phenomenon all over the world despite strict legislation and the threat of punishment. Dog fights are often linked to organized crime, especially illegal gambling and money laundering. Although there is usually no factual evidence to support this link, dogfighting in a criminal context remains synonymous with animal cruelty, violence and illegality. Conducting ethnographic research on this phenomenon is therefore an important task for criminologists who wish to explore the connection between organized crime and dogfighting.

\footnotetext{
${ }^{1}$ Dogfighting can be described as "The act of baiting two dogs against one another for entertainment or gain" (Evans et al. 1998).
}

Daan van Uhm

d.p.vanuhm@uu.nl

Dina Siegel

Dina.s@uu.nl

1 Utrecht University, Newtonlaan 231, 3584 BH Utrecht, The Netherlands 
There is a wide range of theoretical approaches spread across different disciplines to explain the relationship between dogs and humans, varying from a focus on dogfighting as a commodity and a source of wealth, to viewing dogs as a source of symbolic meaning of the relationship between humans and animals (Beirne 2009; Harding 2010, 2012, 2017; Maher and Pierpoint 2011). Environmental scholars in particular seek to explain interactions within nature 'in order to assess the impact of human society on the environment and vice versa' (Brantz 2010: 4).

The power relationship between humans and dogs is a central theme in studies on dogfighting (Evans et al. 1998; Harding 2012; Kalof and Iliopoulou 2011; Yilmaz et al. 2015). In comparisons with human combat sports such as boxing and wrestling, a frequently heard argument pertains to free will and rational choice. The assumption is that martial arts practitioners make their own calculations and decisions, while dogs are manipulated and coerced by humans. To counter this argument, dog owners and organizers of dogfighting events claim that, in their natural environment, dogs attack and fight each other for territory, mating partners or food, or to protect their owner or his/ her property, led by their natural instincts. Fights between stray dogs usually serve as an example. If these dogs are expressing their 'free will', then dogfighting can be justified as a natural sport, they argue. Ethical questions about blood sports are not, however, the central theme of the present study. Instead, we will present and analyze the dynamics, organization and social world of the actors involved in dogfighting.

Firstly, we consider dogfighting as a product of tradition and historical continuity, a leftover from periods in history when it was both legally and socially acceptable as a popular way to manifest power and wealth and to entertain the masses. Dogfighting has been found all over the world (Fleig 1996; Evans and Forsyth 1997; Harding 2010, 2012; Kalof and Taylor 2007).

Secondly, we discuss how illegal dogfighting is a result of criminalization. Banning specific goods, services or activities does not make them disappear, as illegal markets usually emerge that attract criminal actors (Landesco 1929; Hulsman 1986; South 1998). Conducting illegal activities is not only a quick way to earn money, but may also serve to alleviate boredom, satisfy a thirst for adventure or even to voice protest against the power of 'softies', namely those who cannot tolerate 'bloody consent' and therefore seek to prohibit dogfighting.

Thirdly, dogfighting signals belonging to a specific social environment that encompasses a wide range of society, from rappers to gangs and politicians. Socalled dog-men and dog-women (and/or cyber dog-men and women) have their own codes of behaviour and professional argot. Reputation, status and trust feature prominently in their communications (Kalof and Taylor 2007; Harding 2010, 2012, 2014; Yilmaz et al. 2015). Nowadays, dogfights are also advertised on the Internet. Not only does this enable the event organizers to facilitate the organization and popularity of these events and provide factual information on specific events, breeds and qualifications, but it also gives them a platform from which to disseminate messages of power, non-conformism and protest against existing policies and legislation. 


\section{Historical and geographical aspects of dogfighting}

As early as 2100 BCE, Hammurabi, the king of Babylon, armed his warriors with fighting dogs. Later in history we find more examples of dogs being used in battles and conquests, such as during the Persian king Kambyses' campaign in Egypt (525 BCE) (Fleig 1996). Greek vase paintings show dog fights in ancient Greece (Poulsen 1922) and today's tourist guides in the Colosseum tell stories about English Mastiffs fighting gladiators, other animals and each other, in the days of the Roman Empire.

In the twelfth century, dogfighting was considered as a respectable form of entertainment by the British gentry (Homan 1999). In the sixteenth century, Henry VIII accompanied the Spanish king Charles V with an army of soldiers and 400 Mastiffs, while Napoleon ordered the use of fighting dogs to defend the settlements in Alexandria (Fleig 1996; Cummins 2003).

The British have always had a special relationship with dogs. For centuries, they have held more dogs in private ownership than the citizens of any other country in the world (Vesey-Fitzgerald 1948: 553; Harding 2012). During the sixteenth and seventeenth centuries, dogfighting, similar to other animal baiting entertainment, was popular and enjoyed support from royalty, and many noblemen became commercial dog breeders (Evans and Forsyth 1997). Aristocrats also bet on their own dogs in fights pitting dogs against bears (Brownstein 1969). The popularity of dogfighting reached its peak in the eighteenth century, when dog fights were a common sight at festivals and folk celebrations (Kalof and Taylor 2007; Harding 2012).

At the beginning of the nineteenth century, when dog breeders started to cross terriers with bulldogs, dogfights became more widely popular among gamblers (Harding 2010, 2012). Gambling has always played an important role in dogfighting. Dogfights charged entrance fees and dogfighting was considered as a socially respected and profitable sport in many European countries, including the Netherlands (Homan 1999). By the end of the nineteenth century dog fights were being professionally organized and subject to detailed rules and codes of behaviour. For example, only dogs of the same weight and sex were allowed to fight each other. Many of those rules are still in force today (Harding 2014; Harding and Nurse 2015; Yilmaz 2016).

In Japan, dogfights involving Tosa dogs (also known as the Japanese Mastiff) were popular betting venues, but Tosas were banned in Britain. Tosas come from the Japanese area of Kochi and were considered as 'fighting dogs' as far back as the sixteenth century during the reign of Shikoku Chosokabe Motochika. Samurais often encouraged warriors under their command to attend these fights to raise their moral and learn about courage. Betting was not a part of these fights. Japanese dog owners consider dogfighting as inuzumo, literally 'dog sumo', a traditional sport with strict rules in which only male dogs of a specific weight (around $80-90 \mathrm{~kg}$ ) can participate. ${ }^{2}$ Considered a national tradition, similar to sumo wrestling and whale hunting,

\footnotetext{
2 'The fight starts with a ceremony, in which dogs enter the ring in a kesho mawashi, a special dress and belt similar to those worn by sumo wrestlers. The goal of the battle is not to harm or kill, but to dominate the opponent. The winner is always acclaimed, dressed once more in ceremonial clothes'. From personal communication with the owner of a fighting dog, November 2020.
} 
they are also a tourist attraction. Tosa dogs are still highly praised today ${ }^{3}$ (Newsweek 2016).

Dogfighting is also a popular sport in Afghanistan and Nepal, especially in rural areas. In Afghanistan, dog owners are usually former soldiers. The Taliban banned dogfighting, but today contests are often held openly as a 'village sport' in the countryside (Yilmaz et al. 2015).

In the Soviet Union, illegal dog fights were organized in remote parks and forests. In the 1990s they moved to more central locations and became regular weekend events. Each participating dog owner paid a fee and the winner took all. Sometimes dog owners bet everything they had: vehicles, dachas (summer houses), thousands of dollars. ${ }^{4}$ In contrast to Japan, Russian dog fights have always been seen as a form of gambling first and as a sport second. In other former Soviet republics, dogfighting became popular after the economic reforms of the 1990s. In Kazakhstan, international contests have been held regularly since then, attracting participants from Asia and Europe, who stand to win a luxury car if their dog comes in first. In Uzbekistan dog fights are held at dog exhibitions. ${ }^{5}$ In Azerbaijan, Georgia, and the Asian parts of Russia, dogfighting is still a popular phenomenon.

The tradition of dog fighting was brought from Europe to the United States at the beginning of the nineteenth century and was advertised by the United Kennel Club. In his novel 'White Fang', the famous American writer Jack London described dogfighting as a matter of the survival of the fittest, with the 'superdog' coming out as the winner (London 1998). In the United States dogfighting was a professionally organized activity until it was banned in 1874 .

\section{Criminalization and dogfighting}

Running parallel to the popularity of dogfighting was opposition to it, especially from the Church. Theatres also considered dogfighting as competition, as royalty was the main patron of all forms of entertainment (Evans and Forsyth 1997: 63; Harding 2012). Today, dogfighting has been criminalized in all but a few countries, though legislation varies and includes a wide range of definitions, most of which are based on cruelty to animals. However, this cruelty is usually treated as a minor offense against property and not as a real crime (Beirne 2007: 62; Harding 2017; Harding and Nurse 2015).

In the 1980s, there was a debate in the Netherlands concerning the desirability of an absolute prohibition on organized dog fights. Following reports in the media

\footnotetext{
3 The local baseball team is called Kochi Fighting Dogs.

4 Later the rules changed and dog owners acquired sponsors (often local businessmen), who would receive $80 \%$ of the winnings if their dog won. Businessmen were considered 'honourable guests' at the contests (Lenta.ru 2017). 'The 1990s even saw the rise of a legendary canine hero in the Moscow region, Borya, the invincible American Stafford terrier who allegedly never lost a fight. He died at the ripe age of 16, and his record still stands today', from personal communication with a participant in dog fights, November 2020.

5 From personal communication in November 2020.
} 
that dog fights were being held in the Netherlands at which the animals would inflict serious injuries on each other, an Advisory Committee on Aggressive Behaviour of Dogs was set up by the Ministry of Agriculture and Fisheries on the $10^{\text {th }}$ of June 1988. This Committee concluded in their report that criminal law and the laws on gambling did not provide a good basis for legal action against dogfighting. The Committee recommended a prohibition on allowing dogs to participate in dogfights. This recommendation was included as a draft proposal for the amendment of the Animal Health and Welfare Act. After due deliberation, parliament decided that an absolute prohibition on organizing or causing animals to participate in animal fights was needed and it became part of the Animal Health and Welfare Act, article 61, paragraph 1 in 1992. This ban is still in force.

Currently, Article 2.14 of the Animal Law Act prohibits organizing (par. 1) or participating in (par. 2) dogfights in the Netherlands. Violation of this article has been classified as a criminal offense. Article 8.12 paragraph 1 of the Animals Law stipulates that conduct in violation of the aforementioned article can be punished with imprisonment not exceeding three years or a fine of the fourth category (max. $€ 20,500)$.

However, as is often the case when activities, services or goods are criminalized, prohibition creates illicit markets. Unlike other baiting sports, dogfighting was a pastime that could be conducted in relative secrecy (Atyeo 1979; Foran 1994), so when dogfighting was criminalized in England, its popularity actually increased, especially among the lower classes, although the upper classes and the nobility also continued to attend these events in secret (Evans and Forsyth 1997: 63). It is perhaps ironic that the very same people who contributed to dogfighting being defined as a socially accepted form of entertainment later redefined it as being offensive. By defining dog fights as illegal or no longer legitimate 'they placed the people who continued to engage in them in marginal positions' (Evans and Forsyth 1997: 63).

Illegal dog fights, like other illegal gambling activities, are often linked to organized crime. Organized crime groups' involvement in gambling is over-documented, from films to media news and scientific reports. Traditional forms of gambling include number bets, horses and dog racing, sports and card games. Albanese (2018) distinguished different types of illegal gambling. One such activity involves animal fighting and betting on dogs and cocks for high stakes. 'Customers bet a total of ' $\$ 5,000$ and $\$ 200,000$ on a single fight, averaging \$100,000 per fight' (Albanese 2018: 275). In addition to illegal gambling, other criminal activities may also take place during dog fights, such as illegal drugs and weapons trafficking (ibid). A recent case investigated by the Organized Crime Drug Enforcement Task Force (OCDETF) in the United States targeted a drug trafficking organization that had allegedly organized and conducted large-scale illegal dogfighting operations throughout the Northern District of Florida between 2014 and $2019 .{ }^{6}$

According to Kalof and Taylor (2007: 325), 'as participants in underground organized crime activity, dogfighters not only make large amounts of money, but they also participate in numerous peripheral crimes, including drug dealing and use,

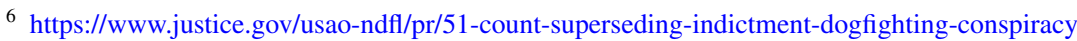


gambling and theft.' The most violent dogfighters are said to be gang members who attend organized fights to gamble and traffic in drugs-_'drugs, gangs, dope, dogs ... they all go together' (Gibson 2005: 6). Bell (2008) studied the rise of clandestine and illegal dogfighting in the northeast of Scotland and linked it to underworld drug dealing. He reported that amongst the drug dealing fraternity it is seen as a mark of 'prestige' to own a top fighting dog or even to be invited to attend a dogfight. Smith (2011: 14) argued that dogfighting is a form of organized crime, typical of urban criminals, a criminal fraternity, which he describes as a 'mix of working and underclass men including travellers, thieves, drug dealers and gangsters'. This description seems to support the general idea that people with vicious dogs are dangerous criminals. In addition, there are some journalistic examples that refer to traditional organized crime groups, such as the Yakuza in Japan, which allegedly sponsors dogfighting events and threatens proponents of a ban on dogfighting (e.g. Japanese Animal Welfare Society) (Newsweek 2016).

It has also been argued that some of the criminal syndicates involved in largescale dogfighting rings are simply too large to effectively combat at the local level (e.g., Chilakamarri 2015). For example, Heger (2011) discussed the possibilities of using the anti-mafia RICO Act to bolster dogfighting prosecutions and concluded that 'application of RICO may better serve criminal law objectives than current Animal Welfare Act prosecutions (...) require[ing] investigators to look beyond the animal cruelty and into the surrounding criminal activities - gambling, drug use, etc.that often surround dogfighting ventures' (Heger 2011: 270).

\section{The social world of dogfighters}

Dogfighters have their own codes of behaviour. Reputation, status and trust are important aspects of their social lives (Harding 2010, 2014; Evans and Forsyth 1997). As Geertz observed in his ethnographic study of cockfighting in Indonesia: 'Much more is at stake than material gain: namely, esteem, honor, dignity, respect - in a word...status' (Geertz 1973: 433). From this perspective, dogfighting can be seen as a form of 'status gambling', a contest between the participants' status, or, to use Goffman's term, 'a status bloodbath' (Goffman 1961: 78). Winning is paramount to building reputation and status (Harding 2010, 2012; Maher et al. 2017).

Dogfighting also signifies belonging to a specific social environment. Watching the fights, showing up regularly either as an observer or a dog owner means joining and investing in a sub-group and creating social ties, something that often leads to friendships. These new relationships can also be beneficial in other social spheres. Trust relationships are forged on the basis of mutual interest, belonging to the same milieu and being familiar with the cultural codes of behaviour and the argot (Lawson 2017). This trust can form the basis for long-standing relationships or friendships, while social media facilitate and spread fascination with dogfighting (Harding 2012; Harding and Nurse 2015). They provide a wide range of possibilities to form relationships, observe battles from up close, join in with evaluating the participating dogs and keeping up-to-date with international events, both online and offline (Smith 2011; Lawson 2017). There is even a category known as cyber dog-men, who learn 
how to treat and train their dogs by taking advice and tips from other members of social media platforms (Gibson 2005).

Some researchers argue that dogfighting is a male-dominated activity, the basic ingredients of which are sexual potency, masculinity and displays of aggression (Kalof 2007; Evans et al. 1998). Similar to cockfighting or bullfighting, dogfighting is an activity in which there is 'a clear juxtaposition between owning fighting animals and aggressive masculinity' (Kalof and Taylor 2007: 321). The dogfighting phenomenon has been gendered in many studies. Traditionally, betting on horses and dog races has been regarded as gambling for working-class men (Evans et al. 1998). However, several researchers in the UK have found that women also frequent betting shops, especially in the mornings. Cassidy's respondents ascribed male dominance in betting shops to 'a natural preference by men for activities that involve calculation and deduction and to the absence of this preference among women' (Cassidy 2013: 18).

\section{Research methods}

Our research was conducted between 2018-2020 as part of a larger study on highrisk dogs in the Netherlands (Van Wijk et al. 2019). Our role as criminologists within the project was to collect data and analyze the dogfighting phenomenon in the Netherlands, including its different stages, the actors involved, and the social organization behind the fights.

In this research we used a mixed methodology, including interviews, observations, analysis of police files on dogfighting and online methods, to analyze the organization, dynamics and social world of the actors involved in dogfighting. We derived most of our information from 26 interviews with respondents, including representatives of law enforcement, dog traders, dog breeders, persons involved in dogfighting and vets.

An important method for finding respondents was through snowball sampling: future participants were recruited from among their acquaintances, which is useful in contacting members of a population that are difficult to access (Goodman 1961). All respondents provided their informed consent, and all interviews were conducted in private and voice recorded unless the respondent declined. Interviews lasted one hour on average. To ensure confidentiality, pseudonyms are used in place of the respondent's real name.

In addition, we conducted observations at various dog events, including the training of dogs and international dog shows. The observations provided us the opportunity to obtain essential information by observing and interpreting behaviour and everyday practices. Furthermore, we were able to engage in informal conversations and chats throughout the study period, which was helpful in clarifying and confirming data collected from interviews. Data from participant observations were collected through detailed field notes.

We also joined a number of Facebook groups, where we were able to analyze communication between dogfighters and obtain information about dogfighting events. We first submitted a request to be allowed to participate in the Facebook 
groups, after which we received permission after a few days. In addition, we were given access to several ongoing police investigations and completed police files, including transcripts of WhatsApp communications between dogfighters, pictures and homemade videos from dogfighters in the Netherlands. The latter gave us a deeper understanding of the phenomenon, while also indicating the importance of social media in the organization of dogfights in general, and in the Netherlands in particular.

We analysed the empirical data with NVivo and triangulated our data by employing the different research methods of data collection (Patton 2015). Each research method has its limitations. For instance, the interviews include subjective views and police files include only recorded cases that were uncovered. However, an attempt was made to overcome the inherent limitations by using different research methods to approach the phenomenon. Moreover, given the in-depth and localised nature of our study, the transferability of our findings may be limited to other settings, but we believe that the theoretical propositions outlined in this study are transferrable nonetheless (see Yin 2009).

\section{Dogfighting in the Netherlands: the stages}

\section{Training}

Fighting dogs, like fighting humans, undergo extensive training to increase their chances of winning. They are exercised under controlled conditions and kept isolated from other dogs.

The process of preparing a dog for a fight is known as the keep. ${ }^{7}$ Not only are the dogs trained in preparation for the fight, they are also tested for gameness. Gameness is defined as the behavioural characteristic of 'not stopping' or 'finishing the task' despite the threat of substantial injury. Among dogfighters, 'gameness' means that a dog will fight to the bitter end, even if the limbs are broken and mutilated (Harding 2012, 2014). As one dogfighting participant from Rotterdam, who had attended multiple dogfights across the Netherlands, explained:

"As soon as the dog becomes immensely fixated on the other dog, does not turn away, goes for it and bites, you are already in a 'game test'. Then gameness is in, and only then it gets interesting."

Routines used to train dogs during the keep include cardiovascular training, such as running on a treadmill (adapted for dogs) to develop fitness and endurance, and strength training involving a fire hose or making the dog pull weights, such as a loaded cart or sled. These exercises are to enable a dog to last longer during a fight and inflict more damage on its opponent. In addition, fighting dogs are given

\footnotetext{
7 The keep is described in police files as "a rigorous feeding and training program designed to prepare and train a dog for a dog fight, usually four or six weeks prior to the fight. Unless it is training, a dog in the keep is usually kept separate from other dogs.".
} 
anabolic steroids to make their muscles grow faster and increase their strength. In order to test the skills of a fighting dog during the keep, bait-dogs are sometimes used. Bait-dogs is a term for dogs that are considered cur, i.e. not fit for purpose as fighting dogs. They can, however, be used as 'bait' for a fighting dog during its training. ${ }^{8}$

\section{Preparation}

Before the real dog fight starts, the dogfighters settle on a location, date and time, the maximum weight of the dogs, how many spectators are allowed to be present and who will act as judge. An example is given in the WhatsApp conversation below between a Dutch dog fighter (NL3) and an Eastern European dog fighter (V1), discussing the conditions for the fight:

\section{WhatsApp conversation 1}

NL3: [Person] is judge.

NL3: [Person] is opponent.

V1: Only one roll.

V1: $45 \mathrm{~min}$.

[...]

NL3: Okay, so 12th dec, Holland your venue @ 9 pm, 17 kg/37.5lbs $500 €$ bet, 3 guest per side max, REF [Person], agreed?

Respondents explained that a dog should not exceed the set weight. They may be lighter, but this would work to their disadvantage, as dogfighters associate weight with strength. As the WhatsApp chat illustrates, the financial aspect of dogfighting in the Netherlands is often arranged in advance. Police files show that the bets placed on dogfights can range between $€ 500$ and $€ 5,000$ and that payment must be made eight weeks in advance. Informants explained that spectators pay an entrance fee of around $€ 100$. In addition to their travel and accommodation costs, judges receive $10 \%$ of the pot, and a fixed fee of $€ 500$ was also mentioned.

Once the dogfighters have trained their dogs and agreed upon the conditions of the fight with their opponents, they start planning the event. The location is announced a few days in advance, often via Facebook and/or WhatsApp. These secret locations can be a shed on a remote industrial estate or even the living room, bedroom, or garage of a dogfighter's home. Dogfights are often held on weekends and most fights are recorded: sometimes they are livestreamed directly and shared via social media. This also makes it possible to organize online betting.

\footnotetext{
${ }^{8}$ Cur is a term for a dog that is not game, shows signs of giving up, or stops fighting.
} 


\section{The fight}

Dogfights take place in a space called the pit. This space is generally surrounded with plywood and measures four by four meters wide and $60 \mathrm{~cm} \mathrm{high,} \mathrm{although}$ police files report differences. Most pits have a carpet or tarpaulin floor to make it easier for a dog to pull its opponent along. Before the fight starts, there is usually a roll where the dog must demonstrate gameness. Once the roll has been completed and the dogs have been weighed by the judge, the fight can commence. Dog fights can last from between 10 min up to over two hours. The goal is for one dog to inflict so much damage on its opponent that the other dog gives up or the judge ends the match. The dogs continue fighting until one of them makes a turn, turning its head and shoulders away from the opponent. After a turn, the dog who made it must scratch to his opponent. Scratching is defined as crossing the scratch line, which is drawn in the centre of the pit, and attacking the opponent within a specified amount of time, usually 10 to $30 \mathrm{~s}$. If a dog fails to scratch, his opponent is declared the winner and titles are awarded by the judge. ${ }^{?}$

\section{After the fight}

After the fight, the dogs are evaluated by the dogfighters, as illustrated in WhatsApp conservation 2 between a Dutch dog fighter (NL2) and an Eastern European dog fighter (W1), reflecting upon the 'qualities' of the dogs:

\section{WhatsApp conversation 2}

W1: The dog is a killer apparently.

W1: 3 match 29 min.

W1: But now he is blind.

NL2: His one IS the best dog lost in to kid.

NL2: But after, hé asked to match [dog] for 5000 euros if hé lost, nothing if hé won, and [person] did not accept.

NL2: You can not compare [person's] dogs to [person]'s shit dogs.

W1: [Person] is à peddler and $80 \%$ OF HIS DOGS ARE CURS.

Once the fight is over, dogfighters determine the damage to their dog. If a dog has been killed, it is dumped or buried in a remote area. If it has been injured, most fighters will try to cure it themselves using veterinary drugs or take it to a trusted veterinarian.

\footnotetext{
${ }^{9}$ Failure to scratch is the most common way in which a fight ends, but other reasons why a referee may end the fight include the death of one of the opponents or when a dog literally jumps out of the pit in order to escape the opponent.
} 


\section{Actors in dog fights}

There is no "Dog Mafia," i.e. a strictly hierarchical professional criminal organization involved in organizing and sponsoring dogfights in the Netherlands. But there are fluid alliances formed by various international actors who find each other through social media or at dog shows. Groups involved in organizing dog fights form flexible partnerships in which 'brokers' play a central role due to their 'know-how' and wide network of social contacts. Even though dogfighting takes place in clandestine settings, these networks often have close relationships with legitimate dogrelated activities. During our observations we found that most participants knew each other despite having different roles in the network.

\section{Organizers}

Figure 1 illustrates how one particular group involved in dog fights operated in the Netherlands. The core members of the group organized fights throughout the country. They were not only responsible for organizing and participating in dogfights, but also for the commercial breeding and trading of Pitbulls for dogfights.

The leading actors, I-1 and I-2, were responsible for breeding and training the dogs, financing the dogfights and maintaining contact with other dogfighters. The leading actors have their private kennel where they bred puppies from successful fighting dogs; descendants of champions were selected. They also prepare dogs for dogfights by training with them. In between training sessions, the dogs in the yard are kept in kennels and taught to remain quiet to avoid unwanted attention. Several times a year the dogs are taken to events to demonstrate their strength and endurance to other participants. Because of his knowledge, I-2 is invited by organizers of

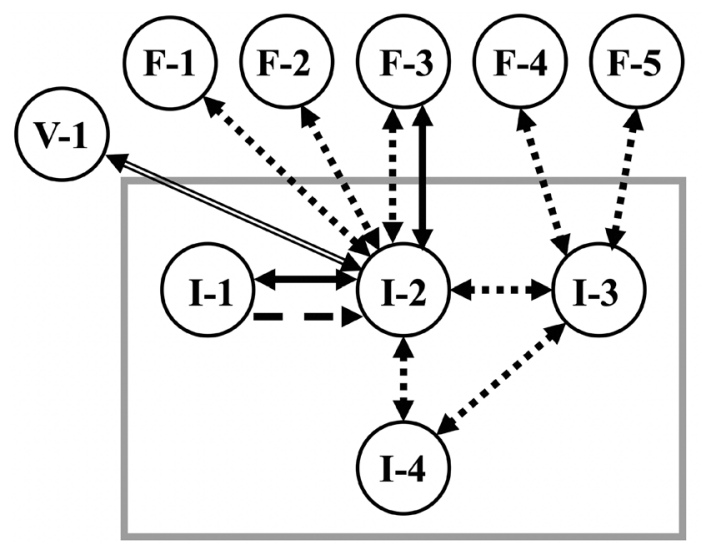

[... Organization/participation

- Breeding/trading

- Financing dog fights/trade

= Veterinarian assistance

Criminal association

Fig. 1 Organization of dogfighting network in the Netherlands 
dog shows to act as a judge, but together they took decisions concerning breeding, trading and fighting. ${ }^{10}$ The two other core members of the network, I-3 and I-4, were mainly involved in the organization of the fights, such as finding a suitable location, and taking care of dogs. The fights often took place in the home of one of the dog fighters, in bedrooms and living rooms, where they build a pit. Television and radio turned on to overshadowing the noise associated with the fights. F-1 to F-5 were participants in the dogfights, but were not core members of the group. Since the dogfighters of this group regularly used the services of veterinarian V-1, to take care of fighting dogs, this vet can also be considered as part of the network.

\section{Participants}

There is not just one category of dogfighter: we found different groups and individuals, ranging from street rollers in Rotterdam who are in trouble with the police, and petty drug dealers who participate in dog fights to pay off their debts, to 'family dogfighters' who organize and participate in clandestine dog fights that do not admit spectators. They know each other and regularly meet at legal dog shows. The main purpose of these dogfights is gambling and they usually take place at the house of one of the participants. In this category we found both male and female participants and spectators and even children at dogfights. A police investigator involved in a dogfighting case shared his experience with us:

"And then you see a video of a room, with a two-and-a-half-year-old child sitting in his high chair, just sitting there and watching the fight..."

He continued:

"They are on welfare benefits, come from the lower social classes and are faced with all sorts of financial problems, so they cannot invest much. The little money they make is spent on their dogs and that is only just enough, because they are also in debt. They are known to various agencies. These are the types of people we often encounter."

But there is also another group of participants, namely the dog-men. Police are aware of around ten middle-aged men of Dutch, Turkish and Moroccan origin, who own 40 to 50 fighting dogs. They are professional dogfighters with international reputation and consider dogfighting as a sport with its own rules and a long history and advocate for its regulation.

\section{Judges}

Dogfighting judges are often highly regarded in the social world of dogfighting for their experience, knowledge of dog breeding, status as a fighter, or as a judge at dog

\footnotetext{
${ }_{10}$ They transferred money for various services to foreign contacts via financial institutions such as Western Union.
} 
shows for high-risk dogs. The choice of judge depends on the dogfighters' network. Judges may be resident in the Netherlands or flown in from abroad (expenses paid) for a specific dog fight. According to our respondent, a police investigator, referring to an American judge invited to a Dutch dog fight:

"So they have judges come over, they pay well for it, [Person] from America he is a multi-millionaire and he comes here to judge dogs, but he has already been convicted three times for gaming there. But yes, he [the judge] pays and continues."

The main factor in deciding on the choice of a judge is their reputation for combining expertise with fairness and neutrality. The judge must either know both dogfighters or neither one in order to ensure his or her neutrality when adjudicating the fight.

\section{Veterinarians}

Some dogfighters have well-established relationships with veterinarians they can visit if their dog is badly injured in a fight, while others treat the animal's wounds themselves, for example with antibiotics. Dog fighters are more likely to use the services of a vet if they can trust him or her not to make a report. Injured dogs being brought to a veterinarian or the discovery of a dead dog with its registration chip cut out can be important indicators of dog fights. According to a police official who investigated a dogfighting case in the Netherlands in 2018 and 2019:

"We saw that the vet had been the doctor of those [dogfighters] for more than ten years and that dogs were brought there with some regularity with special injuries, even with broken legs. They knew each other very well and eventually it turned out that the administration was not in order, especially for a number of specific fighting dogs. A patient card had been drawn up and we knew from other conversations that there were underlying invoices, but they were absent. Ultimately, his digital administration was confiscated and it turned out that more than 50 invoices were missing."

\section{Outlaw motorcycle gangs}

Surveillance of the site where dogfighting activities took place provided indications that members of outlaw motorcycle gangs were involved in the protection of these fights. A police investigator, who investigated both animal welfare cases and organized crime cases, explained in detail how motorcycle gangs were linked to dogfighting:

"In Rotterdam we came across cases where members of motorcycle gangs were linked to dogfighting. This was revealed via police information. (...) It turned out that motor club member *** had organized the security during the event. This is a clear example of the relationships between crimes." 


\section{Reputation, trust and gender}

Respondents did not always perceive their illegal activities as being 'wrong' or 'problematic'. They viewed dogfighting as nothing more than a 'sport' with a long history of rules and traditions and argued that it should not be judged as an illegal activity. Within the culture of dogfighters, the use of professional terms such as gameness, curs or roll plays an important role and they also use these terms when communicating in Dutch. In addition, they refer to a traditional system of titles to value their dogs. When a dog wins one fight, they place $1 x W$ next to its name. After winning three fights, a dog is considered a champion and given the title $\mathrm{CH}$, while emerging victorious from five fights makes the dog a grand champion and confers the title $\mathrm{Gr} \mathrm{CH}$. Based on WhatsApp chats and interviews a champion in the Netherlands is worth $€ 2000-3000$ and a grand champion can be worth more than $€ 5000$. Dogfighters put these titles in front of the dog's name in pictures, dog fight announcements, and on social media posts (see WhatsApp chat 3 between NL1, a Dutch dog fighter and F1, an Eastern European dog fighter and breeder).

\section{WhatsApp conversation 3}

NL1: Breeding with ch [dog].

NL1: If $i$ win with these female match .

NL1: I give you money $i$ win.

F1: $i$ spick mein friend.

[...]

NL1: I Bred [dog] with [dog].

NL1: I give u you pup ch [dog] $x$ [dog].

F1: mein friend nied to maci mony for femel.

The owners of these fighting dogs view the energy and money invested in them as proof that that they 'love' their animals. They claim that fighting dogs have a genetic drive to fight and that it's part of their natural behaviour. As one participant in dog fights explained:

"It's because of that gameness; that dog was bred for gameness, so he shows that. And he actually enjoys it. So if you focus on the fight in that way, together with that animal and you do it as a team [...] they are really doing something fun together."

Where outsiders see a 'skinny' or a 'ravenous' dog, dogfighters see a 'muscular' dog. Training and controlling the weight of fighting dogs is an important element of the game and dog owners and breeders claim that they know what is best for their dog and its breed thanks to their experience and knowledge. For these people, dogfighting is a traditional sport that should be legalized and regulated. As one dog breeder explained during a discussion about the role of fighting from the perspective of dogs: 
"Fighting is good for the dogs, it's their natural drive. By banning it you are doing something that goes against the dog's natural instinct!"

The people involved in illegal dogfighting also often participate in legal competitions where dogs demonstrate their strength and stamina by running on treadmills and participating in weight pulling games. Some dogfighters in the Netherlands were also members of breeding clubs and participated in dog shows. Dog shows are perceived as an important social event where people from all over the world can meet each other. Participation in such events serves two purposes. Firstly, to propagate the idea that dogfighting is a sport that should be de-criminalized and treated like other dog events, such as pulling weights. Secondly, to invest in the reputation of both the dog and its owner. A good reputation allows participants to maintain existing relations and/or create new ones, while also contributing to the group's legitimacy and lobbying efforts.

Dogfighters are proud of their trained fighting dogs and their titles. Dutch dogfighters maintain contacts with dogfighters from Poland, Hungary, Romania, Belgium, Turkey and Lithuania. This international dimension is illustrated by WhatsApp conversation 4 below between a Dutch dog fighter and an East European trader:

\section{WhatsApp conversation 4}

H: Two sent to Turkey.

$\mathrm{H}$ : Already built up in Romania.

$\mathrm{H}$ : So now in Turkey.

Q: Only it works if not, too little space. That is why we work together with Italy, Spain, England and Ireland.

$\mathrm{H}$ : Yes man, we do everything together.

$\mathrm{H}$ : Then they have nothing to say about roles matching selling breeding.

Q: Yes, that's right.

In addition to building up their reputation through trading in fighting dogs and taking them to dog shows, dogfighters share their self-made videos and photos of fights with their international contacts via WhatsApp and private Facebook groups. During our research we participated in closed Facebook groups where European dogfighters communicate with each other. They openly offered and sold their fighting dogs via Facebook and shared images and videos of dogfights to show how strong and muscular their dogs were. Pictures of wounds sustained during fights were also shared.

Dogfighting is often gendered. Some researchers argue that dogfighting is a maledominated activity, of which sexual potency, masculinity and the display of aggression are the basic ingredients (Evans et al. 1998; Kalof 2007). In their arguments masculinity in particular is linked to a macho image, violence and cruelty.

In our study, we found that dogfighting is not exclusively a masculine phenomenon. In contrast to Evans et al.'s (1998) findings about the "masculinity in dogfighting subcultures", we encountered a relatively large number of women heavily 
involved in dogfighting. Women also took part in other activities, such as breeding and training. During our research, we also met women who watched, placed bets on and even organized illegal fights. According to a female dog fighter who drew attention to the role of breeding, taking care of the fighting dogs and family life:

"Women are involved [in dogfighting], in taking care of the fighting dogs, the breeding and the organization of fights. The dogs are part of family life (...). They take care of their animals and train them".

According to a police investigator involved in a dogfighting case in 2018:

"Yes, women also bring their dogs to fights and they also breed them. Imagine a woman living with her son, just a boy, in a house in *** and then you see the blood on the walls, after a fight has just taken place".

\section{Brief conclusion}

In our research on dogfighting in the Netherlands we were unable to identify either a 'dog mafia' or a dogfighting criminal fraternity (Smith 2011). What we found, however, was a wide range of actors involved in training and preparing dogs for a fight and organizing dogfights, varying from young street rollers linked to petty crime and street drug dealing, to 'family dogfighters' who organize fights at their homes, to professionals involved in international dogfighting events who advocate for the regulation of dogfighting as a sport.

In other words, we have tried to gain an understanding of the social world of dogfighters, their fascination with dogfighting, the criminogenic factors, and the persistent taboos surrounding this activity. Our empirical data shows that actors involved see dog fighting as a traditional sport that should be legalized. Fighting dogs would have a genetic drive to fight, part of their natural behaviour, therefore they justify dogfighting as a 'natural sport'.

Dogfighting in general and in the Netherlands in particular can be viewed as the continuation of a historical tradition and the result of criminalization and the subsequent emergence of an illegal market, in addition to the desire of certain individuals to signal their belonging to the specific social environment of dogmen and dog-women. These groups have their own code of behaviour and professional argot. Reputation, status and trust feature prominently in their communications and social media facilitate and advertise their activities.

Open Access This article is licensed under a Creative Commons Attribution 4.0 International License, which permits use, sharing, adaptation, distribution and reproduction in any medium or format, as long as you give appropriate credit to the original author(s) and the source, provide a link to the Creative Commons licence, and indicate if changes were made. The images or other third party material in this 
article are included in the article's Creative Commons licence, unless indicated otherwise in a credit line to the material. If material is not included in the article's Creative Commons licence and your intended use is not permitted by statutory regulation or exceeds the permitted use, you will need to obtain permission directly from the copyright holder. To view a copy of this licence, visit http://creativecommons.org/ licenses/by/4.0/.

\section{References}

Albanese J (2018) Illegal gambling businesses \& organized crime: an analysis of federal convictions. Trends in Org Crime 21:262-277

Atyeo D (1979) Blood and Guts: Violence in Sports. Paddington Press, New York

Bell G (2008) Animal welfare group warns of rise in secret dog-fighting: Sickening crime is often linked with underworld drug dealing. Press \& Journal 3(7)

Beirne P (2007) Animal Rights, Animal Abuse and Green Criminology. In: Beirne P, South N (eds) Issues in Green Criminology: Confronting Harms Against Environments. Willan Publishing, Humanity and Other Animals, Devon, UK, pp 55-85

Beirne P (2009) Confronting animal abuse: Law, criminology, and human-animal relationships. Rowman \& Littlefield Publishers

Brantz D (Ed.) (2010) Beastly natures: Animals, humans, and the study of history. University of Virginia Press

Brownstein O (1969) The Popularity of Baiting in England before 1600: A Study in Social and Theatrical History. Educ Theatr J 21:237-250

Cassidy W (2013) Dog fighting. University of Chicago, Chicago

Chilakamarri V, Eddy E (2015) An Introduction to the Federal Animal Protection Laws. US Att'ys Bull 63:9

Cummins B (2003) Colonel Richardson's Airedales: The Making of the British War Dog School, 1900-1918. Dog Training Press

Evans RD, Forsyth CJ (1997) Entertainment to outrage: A social historical view of dogfighting. Int Rev Mod Sociol 59-71

Evans R, Gauthier D, Forsyth C (1998) Dogfighting: Symbolic expression and validation of masculinity. Sex Roles 39(11-12):825-838

Fleig D (1996) The History of Fighting Dogs. TFH Publications

Foran S (1994) The genetic foundation for behavioral varieties in the American pit bull terrier. University of Connecticut, Hartford, CT

Geertz C (1973) The Interpretation of Cultures. Basic Books, New York

Gibson, H. (2005) "Dog Fighting Detailed Discussion." Animal Legal and Historical

Goffman E (1961) Encounters: Two studies in the sociology of interaction. Ravenio Books

Harding S (2010) "Status dogs" and gangs. Safer Communities 9(1):30

Harding S (2012) Unleashed: The phenomena of status dogs and weapon dogs. Policy Press

Harding S (2014) The Street Casino: survival in the violent street gang. Policy Press, Bristol

Harding S (2017) Aggressive dogs and public image. In: Mills, D. S., \& Westgarth, C. (eds). Dog bites: a multidisciplinary perspective. Books Ltd

Harding S, Nurse A (2015) Analysis of UK dog fighting, laws and offences. Project Report. Middlesex University, London, UK

Heger M (2011) Bringing RICO to the ring: Can the anti-mafia weapon target dogfighters. Wash Univ Law Rev 89(1):241-272

Homan M (1999) A complete history of fighting dogs. Howell Book House

Hulsman L (1986) Critical criminology and the concept of crime. Contemp Crises 10(1):63-80

Kalof L, Taylor C (2007) The discourse of dog fighting. Humanit Soc 31(4):319-333

Kalof L, Iliopoulou MA (2011) Abusing the human-animal bond: on the making of fighting dogs. In The Psychology of the Human-Animal Bond. New York, NY: Springer, pp. 321-332

Landesco J (1929) Organized crime in Chicago. Illinois Association for Criminal Justice

Lawson C (2017) Animal fighting. The Palgrave international handbook of animal abuse studies. Palgrave Macmillan, London, pp 337-362

Lenta.ru (2017) https://lenta.ru/articles/2017/10/06/dogs/ 20 November 
London J (1998) The call of the wild, White Fang, and other stories. Oxford University Press, USA

Maher J, Pierpoint H (2011) Friends, status symbols and weapons: the use of dogs by youth groups and youth gangs. Crime Law Soc Chang 55(5):405-420

Maher J, Pierpoint H, Lawson C (2017) Status Dogs. In: Maher J., Pierpoint H., Beirne P. (eds) The Palgrave International Handbook of Animal Abuse Studies. Palgrave Macmillan, London

Newsweek (2016) 9 January, https://www.newsweek.com/2016/09/09/japanese-dogfighting-494843.html

Patton MQ (2015) Qualitative Research and Evaluation Methods, 4th edn, SAGE Publications, Inc

Poulsen F (1922) Etruscan tomb paintings. Clarendon Press, Their subjects and significance, Oxford

Smith R (2011) Investigating financial aspects of dog-fighting in the UK. J Financ Crime 18(4):336-346

South N (1998) 'Corporate and state crimes against the environment: Foundations for a green perspective in European criminology. In Ruggiero, V. N. South, \& I. Taylor (Eds.), The New European Criminology (pp. 443-461). Routledge: London

Van Wijk A, Lenders A, Van Uhm DP, Siegel D, Van Nieuwenhuizen X, Endenburg N (2019) Hoogrisico honden, een bijtend probleem? Beke \& Universiteit Utrecht, Een fenomeenonderzoek naar bijtincidenten en hondengevechten

Vesey-Fitzgerald B (1948) Dogs in Britain. Nature 162(4119):553-553

Yilmaz O (2016) Dog fighting in some European countries. Int J Livest Res 6:20-25

Yilmaz O, Coskun F, Ertugrul M (2015) Social Aspect of Dog Fighting. Int J Livest Res 5(2):8-12

Yin RK (2009) Case Study Research: Design and Methods, 4th edn, SAGE Publications, Inc

Publisher's Note Springer Nature remains neutral with regard to jurisdictional claims in published maps and institutional affiliations. 